\title{
ÉDIPO E (O ENIGMA D)A VISÃO DAS IDADES
}

\author{
Francisco Murari Pires
}

RESUMO: L'interprétation de la scène inaugurale de l'Oedipe Roi de Sophocle a été constamment poursuivie par des considérations qui visent surtout à bien identifier, d'une manière positive et précise, tous les personnages qu'y sont figurés. On propose, ici, d'explorer plutôt des significations métaphoriques aux vers 15-19, pour ainsi comprendre la référence faite à la vision des âges des personnes qui représentent la communauté thébaine suppliante devant Oedipe comme une allusion dissimulée à l'énigme du Sphinx.

PALAVRAS-CHAVE: Édipo, Sófocles, enigma, Esfinge.

O Prólogo do Édipo Rei de Sófocles parece colocar-nos um enigma hermenêutico. Ao longo de seu desdobramento, algumas alusões textuais (v. 9-10; 31-2; 58 e 147) sugerem a presença ativa de um só sacerdote em cena, o sacerdote de Zeus, que justamente interpelado no início da peça por Édipo, lhe expõe os motivos do afluxo dos tebanos suplicantes reunidos junto aos altares do palácio. Entretanto, logo no começo desta sua exposição, o sacerdote de Zeus, direcionando o olhar de Édipo para a visão da comunidade ali presente diante dele, refere-se a sacerdotes, no plural! Tal é sua fala (v. 14-21):

Bem, ó soberano Édipo de meu país,
vês-nos de que idades assentados
junto a teus altares: uns ainda não a longe
voar fortes, outros com a velhice pesados
- sacerdotes, eu de Zeus -, e estes dos jovens
seletos; já o resto do povo coroado
nas praças assenta, junto ao de Palas duplos
santuários e pelas de Ismeno oracular cinza. ${ }^{1}$

Já em 1816, Bentley, que justamente acusara o impasse do enigma, intentou superar essa aparente divergência propondo corrigir-se o texto do manuscrito: ao invés de hiereis, forma plural atestada no verso 18, adotou hiereus, singular. Mais outros críticos seguiram a via exegética assim solucionadora de um tal enigma supostamente disposto pela tradição manuscrita. Outros críticos, todavia, dissentiram, recusando encaminhar seu entendimento por essa vertente exegética, e antes optaram por confirmar a lição do manuscrito mantendo a forma plural, agora decidida como hieres. ${ }^{2}$

\footnotetext{
Francisco Murari Pires é professor da Faculdade de Filosofia Letras e Ciências Humanas da USP

${ }^{1}$ All', o kratunon Oidipous choras emes,

horas men hemas helikoi prosemetha

bomoisi tois sois, hoi men oudepo makran

ptesthai sthenontes, hoi de sun gera bareis

hieres, ego men Zenos; hoi de t'etheon

lektoi; to d'allo phulon exestemmenon

agoraisi thakei, pros te Pallados diplois

naois, ep'Ismenou te manteia spodo.

${ }^{2}$ Vejam-se as indicações dadas por Bollack, Oedipe Roi, tomo 2, p. 17.
} 
Em 1925, Louis Roussel, reagindo contra a projeção, então já consagrada e difundida pelos comentadores modernos, que percebe nessa cena inaugural a presença de uma multidão de suplicantes/figurantes, reclamou a consideração do princípio hermenêutico por que dever-se-ia pautar a melhor apreciação crítica de um tal texto, dada sua precípua natureza teatral: o ajuizamento das significações operado também pelas implicações de figuração cênica da arte dramatúrgica. ${ }^{3}$ Em sua revisão, logo acolheu a correção proposta por Bentley, a identificar, pois, apenas um sacerdote em cena, o de Zeus. Daí, face ao contra-senso conseqüente a essa correção - hiereus, sacerdote, no singular, entretanto imediatamente antes aludido por bareis sun gera, velhos, no plural - entendeu este último como plural de majestade, a assim eliminar da cena também a pluralidade de anciães. E, para firmar a melhor consistência lógica do texto ${ }^{4}$ - com tanto Édipo quanto o sacerdote referindo-se genericamente à coletividade dos suplicantes como crianças (paides, tekna) - haveria que identificar por esse único grupo etário a distinção dúplice por que o sacerdote inicialmente o descreve, ora dizendo-os filhotes (versos 16-17), ora jovens seletos (versos 18-19).

A figuração cênica comportaria, então, para Roussel, uma reduzida composição bipolar de um velho sacerdote de Zeus mais um grupo de crianças, dualidade quiasticamente estruturada primeiro a destacar sua contraposição de idades - de um lado o muito idoso, de outro os bem jovens -, depois sua distinção meritória - sacerdote eminente, filhos de nobres eleitos. ${ }^{5}$ Em decorrência, mais outras tantas precisões positivas de percepção e de entendimento da cena: Édipo qualifica seus súditos como crianças não porque seja um rei que se comporte paternalmente, mas simplesmente porque assim cabe a um homem de uns 45 anos tratar jovens adolescentes de 14; não é uma multidão, o populacho, que ousa dirigir-se ao rei, mas um grupo de elite; as crianças dispõem-se igualmente em torno dos dois altares palacianos, não muito grandes, provavelmente a comportar em cena apenas entre doze e vinte crianças mais ou menos.

$\mathrm{O}$ que Roussel cuidara em condicionar como apenas uma proposta de versão francesa equivalente em sentido à construção sintática dos versos 18-19 - "Tout se passe comme dans de vers français qui seraient: Je suis un serviteur de Zeus; eux sont des fils de nobles" (ROUSSEL, 1925, P. 169) fixou-se, com a edição do Édipo sofocleano por Paul Mazon em 1958, como fato mesmo de tradução: "O souverain de mon pays, Oedipe, tu vois l'âge de tous ces suppliants à genoux devant tes autels. Les uns n'ont pas encore la force de voler bien loin, les autres sont accablés par la vieillesse; je suis, moi, prêtre de Zeus; ils forment, eux, un choix de jeunes gens" (MAZON, 1958, p.23).

A solução hermenêutica assim equacionada pelos estudos de Roussel e Mazon veio a deparar-se, todavia, com as objeções levantadas por Kamerbeek. Em seu comentário global da tragédia sofocleana de 1967, Kamerbeek delineou uma refutação crítica à tese de Bentley, argumentando que esta, ao buscar resolver um problema concernente à melhor compreensão do texto, acaba intrigando outros, talvez ainda mais embaraçosos. E os assinalou pela simples leitura da tradução proposta por Mazon aos versos 16-19, que justamente adotara a correção de Bentley: "Les uns n'ont pas encore la force de voler bien loin, les autres sont accablés par la vieillesse; je suis, moi, prêtre de Zeus; ils forment, eux, un choix de jeunes gens" (KAMERBEEK, 1967, p. 35). Admitida tal tradução, arrazoa o crítico, como entender-se a referência ao sacerdote no singular, se a referência primeira aos velhos está no plural? Haveria que supor, como já o admitira Roussel, um plural de majestade para hoi bareis (os pesados pela velhice) do verso 17. E, por tal tradução ainda, complica-se outra questão: os ethéon lektoi (os jovens seletos) citados nos versos 19-20 referem a mesma classe de idade que a dos oudepo sthenontes (os que ainda não têm forças para longe voar) dos versos 17-18, como o supõem tanto a tradução de Mazon quanto as análises de Roussel, ou uma outra distinta? Agora, não se têm mais um problema só, mas pelo menos dois! Então, conclui Kamerbeek, é preferível simplesmente aceitar a tradição manuscrita e conviver com o enigma original - posto pela efetividade dramatúrgica da singular presença do sacerdote de Zeus, entretanto uma vez referida no plural -,

\footnotetext{
3 "Il reste que la figuration de la scène est très différente de ce que l'on imagine d'ordinaire. Nous réformerons notre opinion sur bien d'autres points que celui-ci, si nous voulons penser plus que jamais, dans l'étude des pièces grecques, aux exigences du métier et de la réalité, et nous rappeler que, pour les dramaturges grecs comme pour tous les dramaturges, la figuration, aussi bien que la langue et la versification, sert à des fins exclusivement artistiques" (ROUSSEL, 1925, p. 170).

4 "Les treize premiers vers (couplet d'Oedipe) deviennent en effet beaucoup plus logiques."(ROUSSEL, 1925, p. 168).

5 A tradução dos versos 18-19 suporia ("Tout se passe comme dans des vers français qui seraient") esta construção: "Je suis un serviteur de Zeus; eux sont des fils de nobles" (ROUSSEL, 1925, p. 169; sublinhados meus).
} 
bem empenhando-nos ao mesmo tempo por descobrir sua melhor compreensão no que estiver ao nosso alcance hermenêutico.

A. D. Fitton Brown, em um texto de 1952, também levantou ressalvas contra o suposto entendimento do Prólogo sofocleano que realçaria a distinção de faixas etárias - little children, growing lads, and aged priests- na composição da comunidade dos tebanos suplicantes, argumentando, como já antes o fizera Roussel, contra a implausibilidade de se supor um valor de afetividade paternal no modo de tratamento edipiano da mesma como crianças (tekna), especialmente considerando agora a incoerência assim acarretada pela outra referenciação dessa mesma comunidade por Édipo logo no verso inicial, em que ele a destaca como nova: Ó crianças, de Cadmo antigo nova trophe. Tekna, crianças, deve ser entendido como implicando apenas a diferença de idade: the seniority of the speaker contraposta à juventude dos suplicantes. Assim, o agrupamento de suplicantes que se dirige a Édipo seria composto por uma delegação predominantemente jovem, com talvez três sacerdotes idosos. Então bem se justificaria, sustenta Fitton Brown, a propriedade de sua referenciação edipiana tanto por tékna (crianças) quanto por néa (nova): Édipo assim os qualifica porque eles em geral são mais jovens do que ele.

Alan S. Henry, em artigo datado de 1967, aprofundou o alcance da crítica à interpretação tradicional que percebe uma tal conformação etária tríplice na delegação suplicante - young children, aged priests and a chosen band of unmarried youths. Seus argumentos a divergir dessa interpretação reclamam agora precisamente contra a estranheza da inserção do terceiro grupo - etheoi, os jovens adolescentes - em uma tal cena de súplica. Assim, no restante do Prólogo, não se faz qualquer alusão à sua presença, pois paides, a denominação porque a comunidade suplicante é qualificada (versos 31-2 e 142-4), não pode recobrir tanto crianças quanto etheoi. Depois, etheoi, jovens não-casados, compõem membros apropriados a um contexto sacrificial, a requerer a pureza de seu status, como consistentemente ocorre nas Fenícias de Eurípides, nos versos 944-5, em que Meneceu é assim distinguido em oposição a Hemon. E ainda, admitida a existência desse terceiro grupo, o texto sofocleano seria falho em sua estruturação sintática, transgredindo a lei de articulação opositiva formulada pela construção de partículas men ... de, dado que o men de ego men Zenos, contrariamente à tese dos comentadores que seguem a análise de Jebb, não pode ser aqui particularmente entendido como um caso de men solitarium. Observada essa lei sintática, uma primeira articulação men...de contrapõe hoi men oudepo makran ptesthai sthenontes a hoi de sun gera bareis, e a seguinte articulação faz o segundo hoi de (t'eitheon) responder justamente a ego men Zenos.

A mais plena coerência lógica de inteligibilidade da cena, pelo arrazoado de Henry, impõe, então, uma exegese crítica mais drástica de tratamento textual da tradição manuscrita: suprima-se a menção aos etheoi, livremo-nos destes inoportunos jovens! Corrija-se, pois, o texto em: hieres, ego men Zenos, hoi de ton theon, lektoi. ${ }^{6}$ De modo que as correlações men...de operariam duas contraposições: crianças/velhos (sacerdotes) na primeira, eu (sacerdote) de Zeus/eles (sacerdotes) dos (outros) deuses pela segunda. Concluindo, compõem a delegação suplicante apenas crianças e sacerdotes, ambos esses grupos lektoi, seletos uns entre as crianças das mais nobres famílias, os outros entre os mais importantes sacerdotes.

Arthur S. McDevitt, em artigo de 1973, corroborou a tese de Henry, ainda desdobrando outro argumento que mais autorizaria a emenda textual operada por este crítico a eliminar da cena a referência aos etheoi, os jovens adolescentes, não-casados. Assim, postulou o princípio exegético porque a mesma se recomendaria: os aspectos de qualidade visual da peça supostos pelas formulações imagéticas de sua narrativa atualizada por uma concepção cênica do espetáculo teatral. Na cena do Prólogo, Sófocles compõe uma imagem inicial da soberania de Édipo em que o dramaturgo procura destacar o poderio e a autonomia da atuação régia, tanto mais realçados quanto, em contraste, dispõe também um grupo de suplicantes que é antes figurado por uma imagética de passividade e dependência, em estado tal de desamparo porque melhor se comoveriam as diligências do rei em seu favor. Tal configuração inaugural da soberania edipiana, então, entende McDevitt, responderia pela teleologia de ironia trágica porque finaliza a peça sofocleana, a antes firmar a lição da enganosa ilusão desse poderio, apenas aparentemente autônomo e auto-suficiente. Por tais concepções imagéticas bem se justificam as presenças quer dos filhotes incapazes de voar longe quer dos anciães pesados com a idade, ambos desamparados e dependentes, uns por causa da infância, outros em

\footnotetext{
${ }^{6}$ A uma tal cirurgia de amputação textual, a exegese de Henry faz seguir uma plástica filológica que intenta imaginar as possíveis deformações corruptoras da transmissão textual que teriam desfigurado ton theon primeiro em ten theon, depois em entheon, até virar eitheon, a reclamarem, então, sua devida correção restauradora.
} 
razão da velhice. Pelo contrário, o que poderia fazer aqui, em meio a estes suplicantes assim tão frágeis, a presença de um bando de robustos jovens? Toda a perícia da arte dramática sofocleana, que justamente acabara de tramar, por esse contraste cuidadosamente elaborado, efeitos cênicos de teleologia trágica, ficaria, então, negada, caso aceita aquela inserção dos etheoi na cena do Prólogo.

Já R.D. Dawe, em seus estudos sobre o texto de Sófocles de 1973, depois retomados nos comentários condensados de sua edição crítica do Édipo de 1982, admitiu apenas a correção textual proposta por Bentley, consagrando, pois, a lição hiereus. E a melhor entender a passagem sofocleana, elaborou os termos da estruturação de pares polares em que supostamente fora expressa a composição da delegação dos suplicantes, desdobrando assim uma idéia já presente no artigo de Roussel. Para Dawe a delegação é descrita primeiro através de uma oposição dual young children/old man que compõe um par definido em termos de idade, e a seguir por uma outra oposição dual the priest of Zeus/young acolytes que compõe outro par, agora definido em termos de função. ${ }^{7}$

Por outro lado, William Calder III, num artigo escrito em 1959, aventou nova alternativa para solucionar o enigma desencadeado pelas considerações críticas de Bentley. Assim, admitiu o problema cênico implicado pelo acolhimento da lição plural do manuscrito, sob a forma hieres, preferindo contornar diversamente os impasses argumentativos implicados pela suposta cena de "multidão" do Prólogo, especialmente complicada devido a seus desdobramentos conseqüentes à saída dessa "multidão" e concomitante entrada em cena do Coro no Párodo. Calder III propõe que toda a fala do sacerdote de Zeus, ao descrever a comunidade tebana suplicante diante de Édipo, vale-se da figuração constituída pela própria audiência teatral, então devidamente apontada gestualmente. Assim, para a referência alusiva aos sacerdotes (o controvertido hieres do verso 18), o ator recorreria facilmente ao gesto indicativo que os situaria pelas figuras dos sacerdotes sentados nas fileiras frontais do teatro de Dioniso. A composição do Prólogo dispensaria, pois, a inserção de uma "multidão" de figurantes: em cena estariam propriamente presentes, além de Édipo e o sacerdote de Zeus, apenas mais dois meninos "mudos".

A tese de Calder III postulando um tal recurso teatral da audience adress, entretanto, foi mais recentemente questionada, entre outros, por D. Bain, O. Taplin e D. Seale. ${ }^{8}$ Taplin, em particular, sugere que a problemática cena de "multidão" do Prólogo do Édipo Tirano seja equacionada por outro recurso de encenação, pelo qual sua entrada em cena se dá anteriormente ao início da peça, esta se abrindo com "o quadro" dessa multidão já configurado. ${ }^{9}$ Tese de que, todavia, Seale diverge, refutando um tal recurso de "cancelled entry", antes asseverando que não se trata de um "tableau", mas sim de uma entrada inicial conformada ritualmente como uma procissão mesma, a realçar seus aspectos suplicantes carentes e reclamantes de salvação. Mas, adverte ainda este último crítico, há que se ter cautela nesta ordem de apreciações, pois, a delegação suplicante não deve ser concebida numericamente exagerada: "certamente não é maior do que o tamanho do Coro, que a seguir é apresentado como corpo representativo do povo tebano" (SEALE, 1982, p. 215 e notas 1 e 3 na p. 255).

Em 1990 Jean Bollack, por outro comentário monumental da tragédia sofocleana, corroborou a reflexão crítica já antes firmada por Kamerbeek, desdobrando mais razões para também refutar a tese de Bentley e seus partidários. Assim articulou uma conjunção de três ordens de razões: primeiro, hoi bareis reclama a presença plural de velhos na cena; segundo, a facticidade da ocorrência textual de hieres; e, terceiro, a distinção entre sacerdote de Zeus e sacerdotes de outros deuses implicada apositivamente pela referenciação de hieres ego men Zenos (sacerdotes, eu de Zeus). Consequentemente, admitiu o plural hieres, entendendo distinguir os etheon lektoi dos oudepo sthenontes como duas classes etárias distintas.

Todavia, nesse mesmo ano de 1990, outros críticos - Hugh Lloyd-Jones e N.G. Wilson - percorriam a outra vertente da bifurcação exegética ensejada para a solução desse singular enigma textual sofocleano. Assim, mantiveram a correção de Bentley, lendo, pois, hiereus no verso 18. Consequentemente identificaram

\footnotetext{
${ }^{7}$ Nos estudos de 1973 Dawe tende antes a assimilar os dois pares: "Os dois emparelhamentos, por idade e depois por função, não referem necessariamente quatro categorias, mas apenas duas, cada uma considerada sob o aspecto primeiro de idade e depois de função" (DAWE, 1973, p. 206). Já nos comentários de 1982, pelo contrário, afirma antes sua dissociação: “dado que é bem implausível que os eitheon fossem considerados tão jovens de modo a poderem ser descritos como ainda não fortes para voar longe, segue-se que este par de hiereus e eitheon lektoi, distinguido por papel e estatus, provavelmente não é idêntico com o par distinguido por idade em 16-17. Os jovens seletos provavelmente não foram mencionados no primeiro par porque estariam no palco tão próximos ao sacerdote de modo a formar um grupo singular oposto às crianças" (DAWE, 1982, p. 88).

${ }^{8}$ Vejam-se as indicações anotadas por Seale, p. 215.

${ }^{9}$ Veja-se: TAPLIN, 1978, p. 109.
} 
aqueles dois grupos de idade numa mesma classe, e admitiram, sem maiores problemas, que o plural hoi bareis refere mesmo apenas o singular sacerdote de Zeus!

Ao longo desses quase dois séculos de exegese do enigma textual sofocleano, os críticos plenificaram assim atentos exames de questões filológicas várias, englobando plural de majestade, relações estruturais de articulação de partículas, men solitarium, impropriedades lexicais, emendas, correções e supressões textuais. Acumulou-se todo um nexo emaranhado de argumentações que se, por um lado, bem discerniu todas as conseqüentes dificuldades que estorvam a mais plena inteligibilidade lógica da hermenêtica dessa passagem, por outro complicou ainda mais o enredamento do enigma, obrando desfecho paradoxal de um ciclo reiterado de divergências para, entretanto, tão competentes esforços eruditos na busca de uma almejada solução decifradora.

A reflexão crítica assim conduzida centrou seu olhar antes primeiramente sobre a figura sacerdotal, se singular ou plural, efetivamente presente na cena, de princípio encerrando sua visão por um pressuposto epistemológico, a saber, o de que há uma proposição de estrita coerência positiva a ordenar continuamente as significações do texto em sua linearidade constitutiva de referenciações, coerência esta determinada pelas imposições de identificação cênica precisa dos personagens distintamente definidos criados pela arte dramatúrgica sofocleana. A seguir, ampliou naturalmente o campo de sua percepção agora polarizada a visualizar a (en)cena(ção) teatral atualizadora da delegação dos tebanos suplicantes de seu rei Édipo. Visão assim, pois, deslocada, em termos da conceituação aristotélica, da ação trágica enquanto mito, para a ação trágica enquanto espetáculo.

Gostaríamos, neste comentário, de desviar um tanto a mirada desse olhar crítico, situando-o não propriamente na nossa, da crítica moderna, visão da cena, mas sim orientando-o antes para o foco mesmo sobre o qual o apelo do sacerdote de Zeus voltou a atenção da visão de Édipo: horas men hemas helikoi, tu nos vês de que idades assentados.

Para o melhor discernimento dessa visão destacou o sacerdote de Zeus quais eram as imagens representativas da composição da comunidade tebana suplicante diante de seu rei, justamente figuradas por suas respectivas definições etárias. Assim distinguiu:

1. hoi men oudepo makran ptesthai sthenontes: os que ainda não são fortes para longe voar, os filhotes, as criancinhas.

2. hoi de sun gera bareis, hieres, ego men Zenos: os com a velhice pesados, sacerdotes, eu de Zeus; ou seja: os velhos, (assim velhos, os) sacerdotes, (como tal, sacerdote) eu de Zeus.

3. hoi de t'etheon lektoi: os jovens seletos.

Por uma primeira articulação narrativa de contraposição (hoi men oudepo makran ptesthai sthenontes, hoi de sun gera bareis) distingue duas classes de idade de definições opostas: uns, as crianças, a apontar para o princípio, outros, os velhos, a apontar para o fim da vida humana. Todavia, também os associou por similitude caracterizadora de limiar de vida, dizendo as limitações do alcance de suas precípuas capacidades locomotoras, justamente assinalada pelas metáforas respectivas com que as qualificou: para aqueles, a fragilidade de seres aos quais falta ainda a força dos membros; para estes, também a fraqueza, mas agora por morosidade, porque gravada pelo peso dos anos. Em ambos marca o estado limiar, para uns inicial para outros final, de impotência de ação.

Depois, a estas duas classes juntou uma terceira, a dos jovens seletos, que, por sua condição própria de exuberante vigor distintivo, define-se em oposição às outras duas. Assim caracteriza a idade limiar de ação, tempo privilegiado que demarca princípio de feitos heróicos.

Então, se irrelevado o pressuposto epistemológico daquela ótica hermenêutica que ambiciona preencher de indicações precisas e definidas os vazios e alusões que o texto mítico mesmo deixa ambiguamente indeterminados, poder-se-ia apreciar a composição sofocleana desta cena inaugural do desfecho trágico da história de Édipo antes pelo alcance próprio de suas significações metafóricas concernentes aos estados da condição humana. Se assim discernirmos a cena por esta outra perspectiva, o apelo do sacerdote de Zeus, a (co)mover a atenção do olhar e a diligência do espírito de Édipo pela percepção da comunidade (tebana) humana suplicante diante dele, ter-se-ia, na trama narrativa sofocleana do mito de seu destino, uma alusiva reiteração da contemplação do enigma da Esfinge: as imagens do ser de quatro, três 
e dois pés! $!^{10}$ Consideração narrativa de um princípio enigmático de consecução desse destino que novamente defrontaria a distintiva potência heróica de Édipo - a excelência de sua ciência visual - ao desafio de uma reiterada ação salvadora comunitária.

E justamente por um tom também de desafio da potência régia-intelectiva salvadora de Édipo o sacerdote de Zeus conforma o rogo suplicante da comunidade tebana a reclamar a intervenção de seu rei. Assim, retomemos do início a evolução do arrazoamento porque segue essa fala sacerdotal.

Após o terrível flagelo manifesto em Tebas pela presença monstruosa da Esfinge, outra desgraça dizimava novamente o país. Um mar de sangue inunda a cidade, nau adernante batida por rubras ondas, em já aflitivo esforço final de naufrágio, tão mais desesperado quanto impotente, de ainda erguer a cabeça acima não submersa. Por todo o país alastra-se a morte. Tebas perece, pois não atualiza mais os princípios de restauração, renovação e geração de vida. A natureza toda, agora, é só esterilidade, impotencializada toda vida nascente. Fenece o alimento agrário, pois sementes e grãos ainda encapsulados, princípios recipientes de guarda de vida vegetal, não mais germinam fecundantes do ventre térreo, antes embotam e murcham sepultos no chão. Definham nos pastos os rebanhos, massas perdidas de alimento animal. E as mulheres abortam labores de parto, assim infrutíferos, ficando, pois, negado o princípio de natividade que as distingue.

Contágio pestilento de generalizada esterilização mortífera, negação de todos os princípios de fertilidade e fecundidade natural, a impotencializar todos os modos de prolongamento e desdobramento de vida terrena. Peste odienta por ação de deus ignífero que abate, devasta, despovoa Tebas. ${ }^{11}$

Assim o olhar do sacerdote de Zeus diz a crise tebana.

A comunidade de Tebas, face aos terríveis males com que os desígnios divinos a arruinam, duplica uma só reação de enfrentamento da crise: piedosas súplicas. Por um lado, o povo coroado congrega-se nas praças rogando auxílios a deuses tutelares e divindades mânticas, Palas e Ismeno. Por outro, uma delegação comunal alcança os altares do palácio, dispondo-se ali todos assentados com suplicantes ramos coroados, a também buscar o socorro de seu rei, Édipo. Modos de reação comunitária que plenifica a cidade com a fumaça odorífera dos incensos e os sons de peãs e gemidos. ${ }^{12}$

Édipo, soberano zeloso de seu povo, de imediato corresponde paternalmente aos sofrimentos dos filhos comunais já por esses modos manifestamente assinalados. Zelo extremado por que bem acolhe a delegação em pessoa, dispensando mensageiros que afastem o rei das vozes dos súditos. Logo intenta fortalecer a confiança da comunidade lembrando-lhe a fama universal do nome Édipo. Logo proclama plena disposição de socorro, prova de régio condoimento paterno. Então interpela entre os presentes a pessoa do ancião, distinta figura para com propriedade por todos expor as razões de suas súplicas, neles anunciadas por aparências de pavores ou aflições. ${ }^{13}$

E o sacerdote de Zeus, a expor as razões inquiridas pelo rei, então apresenta, a (co)mover o olhar e o espírito de Édipo, a percepção da comunidade diante dele representada pelas distintas idades que conformam o destino da condição humana por seres crianças, jovens e velhos. E mais reforça essa percepção patética do povo tebano expondo as cenas porque o contágio pestilento consome sua existência. A casa de Cadmo despovoa contra o negro Hades enriquecido por gemidos e lamentos.

Mas, ainda que mais razões, precipuamente face a tais desgraças, ensejariam à comunidade postar reverentes gestos suplicantes a seu rei nos altares palacianos? Ou, pelo contrário, assim se projetam impropriedades de confusão ímpia da figura régia com os modos da honra divina?

Não, logo adverte o venerável ancião, eles não têm Édipo por igual aos deuses, antes o consideram o primeiro dos homens nas vicissitudes da vida e nos contatos divinos. Ponderação de entendimento

\footnotetext{
${ }^{10} \mathrm{Na}$ bibliografia por nós consultada, encontramos apenas uma refrência a esta via de interpretação do texto, dada em nota de rodapé na edição e tradução das tragédias sofocleanas por Guido Paduano: "D’altro canto si è cercato di conferire significazione sistematica alla composizione di questo gruppo, leggendovi una criptica allusione all'indovinello della Sfinge e alle tre etá dell'uomo: non único caso in cui la presenza della Sfinge, funzione antropologicamente affascinante e forse determinante nella formazione del mito di Edipo, è stata introdota a forza in un sistema drammatico al quale é sostanzialmente estranea" (PADUANO, 1982). Não tivemos condições, entretanto, de melhor identificar a referência anônima a que o comentador assim alude. Quanto à problemática da integração da figura da Esfinge e do tema do enigma na tradição clássica do mito edipiano, veja-se a excelente obra de Jean.Marc Moret, Oedipe, la Sphinx et les Thébains, Genève, 1984. 11 Sófocles, Édipo Rei, 22-30.

12 Ibid. 1-21.

13 Ibid. 1-13.
} 
sacerdotal que intenta deslindar o ambíguo paradoxo intrigado por aquela súplica à pessoa de Édipo: sim, ela situa reverência piedosa, comovendo-o como a um ser divino, e, todavia, nega-lhe tal estatuto. ${ }^{14}$

Assim devidamente se reconhece o estatuto propriamente heróico do rei, ambiguamente situando seu valor pelo domínio do divino e pela esfera do humano. Por um lado, dizer Édipo não igual aos deuses afirma sua inferioridade em relação ao divino, dissocia-o da pertinência a este âmbito, posiciona-o fora e abaixo dele e, portanto, localiza-o em meio aos humanos. E, por outro, formulando contraposição adversativa, assevera também a apreciação de que sua inferioridade é apenas essa, para com o ser divino, nível absoluto de grandeza superior. Ao reconhecer Édipo como o primeiro dos homens, só inferior aos deuses, o entendimento sacerdotal também admite que a superioridade de Édipo é de tal monta no âmbito humano que é a superioridade máxima por eles alcançável, a qual bem se aprecia medindo-a pelo seu contraponto à superioridade divina.

Pois, afirmar a inferioridade de Édipo para com o divino é verdade tautológica da condição humana, válida seja para Édipo, o primeiro dos homens, seja para qualquer outro, mesmo o mais insignificante, inferiormente último em valor. A comunidade de um destino mortal define a humanitude de Édipo. Já afirmar Édipo como o primeiro dos homens supõe a distinção de um só e único indivíduo, bem destacado acima de todos, singularizado por precípua superioridade de valor. Assim se diferencia ambiguamente o hierárquico estatuto heróico de Édipo no e do âmbito humano: o herói nele se insere pelo fato genérico da condição mortal de seu ser, mas dele também, em certo sentido, se dissocia, pois é situado tão acima que se o projeta, agora pelo valor de suas ações, no seu limiar delimitador, quase fora dele, a tocar o divino.

Dizer Édipo o primeiro dos homens apenas inferior aos deuses, ao lembrar a humanitude homogeneizadora de seu ser, assinala também a heroicidade diferenciadora da história de suas realizações. Édipo, o primeiro dos homens, situa superioridade humana de valor tal que bem se estima sua grandeza inferiorizando-a apenas porque não divina.

A prova da Esfinge, aduz o sacerdote, firmara a fama da excelência heróica de Édipo. Por esse episódio bem se marca a contraposição que distingue a individualidade excepcional do herói perante a comunidade humana, genericamente referenciada na fala do sacerdote pelo nós e pelo todos que compõe Tebas. Então, nenhum dos cidadãos, mesmo vivenciando a crise e dispondo dos recursos informativos e demais instruções humanas presumivelmente respeitantes à questão interrogada pela Esfinge, decifrou seu enigma. Nas circunstâncias de sua chegada adventícia à cidade, a situação de Édipo diante da Esfinge era a mais precária, pois desprovida de todo e qualquer concurso de saber humano. E, todavia, apesar de tal desfavor circunstancial de sua situação humana, decifrou-o. Como entender razões que deslindem a intriga desse fato paradoxal? Tal façanha excepcional de decifração do enigma, reflete a fala sacerdotal, assinala talvez para Édipo a graça do favor divino, pois auxílio humano, qualquer um, certamente não foi: Édipo o enfrentou totalmente exterior, estranho, ao lugar humano que dele estava inteirado. Assim, pelo privilégio do favor divino se concebe o êxito heróico edipiano. Tal é, pelo menos, o entendimento consensual da comunidade: é o que se diz, é o que se acredita. ${ }^{15}$

Então, justamente ecoando a antecedente lembrança alusiva da proclamação inicial de Édipo, também a voz da comunidade tebana reconhece a excelência heróica de seu rei consumada pelo episódio da Esfinge, assim celebrando a fama de seu poder salvador.

Mas essa fama remonta a origem passada, feito encerrado. Agora, a atualidade presente reitera outra crise ruinosa em Tebas por contágio pestilento que igualmente a desgraça. O país necessita, outra vez, poder salvador que socorra seu povo em nova aflição. Daí os imperativos exortativos com que a comunidade, pela fala sacerdotal, suplica a Édipo, o melhor dos mortais, para que reerga a cidade, livre-a dos males que a submergem. Se a pestilência maléfica, flagelo pavoroso, perde Tebas, então que seu justo poder salvador, o rei Édipo, a salve! Ambíguos rogos de súplica, pois tanto assim o sacerdote apela a seu poder salvador, reverenciando-o confiante por sua exitosa prova passada, quanto também assim supõe cobranças, reclamos à figura régia por suas responsabilidades de permanente benéfica atuação comunitária. Pois a crise manifesta a falha desse poder, agora carente de efetividade, assim pondo em suspenso sua fama.. Se a areté heróica dessa potência salvadora edipiana bem se proclama pela realização de seu feito pregresso exitoso diante da

\footnotetext{
${ }^{14}$ Ibid. 31-39. Para o comentário deste diálogo entre Édipo e o sacerdote de Zeus no Prólogo, vejam-se as análises de F. Marshall, 1996, cap. II (Súplica e Responsabilidade), p. 58-93.

15 Ibid. 31-39
} 
Esfinge, agora, assinalada sua falha, implicadamente se questiona a atualidade do poder salvador edipiano, desafiando-o à reiteração de um novo feito. Que Édipo, então, seja sempre igual, ainda poder salvador.

Rogo e desafio do poder de Édipo a outra vez reerguer a cidade, salvar Tebas, dispondo benéfica ação comunal, é também concomitantemente, lembra o sacerdote, superar reiterada prova heróica a, agora, resguardar sua pessoal condição régia. Pois, sapiente advertência: se governarás esta terra, como dominas, com homens mais belo do que vazia é dominar, que nada é nem torre nem nau deserta de homens, sem habitantes dentro. Assim, reclama-se da realeza a obrigação de seu dever precípuo de atuação, que precisamente institui e funda a autoridade de sua soberania: a promoção do bem comunal. Para a figura de poder que Édipo consuma, presente soberano de Tebas, a permanência futura de sua suserania agora depende da persistência atual de sua potência salvadora. Nova prova situa justa confirmação de poder régio por consoante reiteração de excelência virtuosa. A história do destino régio de Édipo e a condizente memória celebradora de sua fama heróica deparam pela pestilência que desgraça Tebas, o tempo crítico em que se decide ou sua unicidade salvadora ou, pelo contrário, sua dualidade primeiro salvadora de comunidade ereta e depois ruinosa dela tombada. ${ }^{16}$

Assim concebida a trama narrativa sofocleana do princípio do desfecho trágico da história de Édipo, a alusiva metáfora da condição humana a lembrar o desafio da Esfinge situaria uma reiteração enigmática porque se move o destino do herói, por ele (con)fundindo os modos de concepção mítica de princípio e fim do poder real

\section{BIBLIOGRAFIA}

BAIN, D. Audience adress in greek tragedy. In: Classical quarterly, 25,1975. p. 13-25.

BAIN, D. Some reflections on the illusion in greek tragedy. In: Bulletin of the Institute of Classical Studies,

34, 1987.p. 1-14.

BOLLACK, J. L'Oedipe roi de Sophocle. Lille, Presses Universitaires de Lille, 1990.

CALDER III, W.M. Resenha crítica de Kamerbeek, the Oedipus Tyrannus. In: Gnomon, 48, 1976.p. 601-604.

CALDER III, W.M. The staging of the prologue of Oedipous Tyrannus. In: Phoenix, 13, 1959.p. 121-129.

CHANTRAINE, P. Resenha crítica de Kamerbeek, the Oedipus Tyrannus. In: Révue de Philologie, 43, 1969.

p. $127-128$.

DAWE, R.D. Sophocles. Oedipus Rex. Cambridge, Cambridge University Press, 1982.

DAWE, R.D. Studies in the text of Sophocles. V. 1, Leiden, E.J. Brill, 1973.

FITTON BROWN, A.D. Oedipus and the delegation.In: The classical review, NS II, 1952.p. 2-4.

HENRY, A.S. Sophocles, Oedipus Tyrannus: the interpretation of the opening scene and the text of 1.18. In: The classical quarterly, XVII, 1967p.48-51.

KAMERBEEK, J.C. Plays of Sophocles. The Oedipus Tyrannus. Leiden, E.J. Brill, 1967.

LLOYD-JONES, H. e WILSON, N.G. Sophoclea. studies on the text of Sophocles. Oxford, Clarendon Press, 1990.

MARSHALL, F. Saber, verdade e poder na tragédia Édipo Tirano de Sófocles. Mimeo, São Paulo, Universidade de São Paulo, 1996.

McDEVITT, A.S. Two notes on Oedipus Tyrannus. In:. La parola del passato, CL, 1973.p. 202-206.

MORET, J.M. Oedipe, la sphinx et les thébains. Genève, Institut Suisse de Rome, 1984.

PADUANO, G. Tragedie e frammenti di Sofocle. Torino, Unione Tipografico-Editrice, 1982.

ROUSSEL, L. Quels personnages sont en scène dans l'exposition d'Oedipe-Roi. In: Révue des Étude

\footnotetext{
${ }^{16}$ Ibid. 40-57.
} 
Grecques, XXXVIII, 1925.p.167-170.

SEALE, D. Vision and stagecraft in Sophocles. London, Croom Helm, 1982.

SOPHOCLE. Tome II, texte établi par A Dain et traduit par P. Mazon. Paris, Les Belles Lettres, 1958.

TAPLIN, O. Greek tragedy in action. Cambridge, Methuen, 1978.

Organon, Porto Alegre, nº 27, julho-dezembro, 1999, p. 57 - 70 